\title{
ANNOUNCEMENTS
}

The Royal College of Pathologists

London Symposium

Infections in Pregnancy - Problems for Mother and Baby

Wednesday 22nd November 1995

to be held at The Royal College of Pathologists, 2 Carlton House Terrace, London SW1.

\section{Provisional Programme}

09.30 Registration and Coffee

Chairman's Introduction-Professor Dame Rosalinde Hurley (Queen Charlotte's and Chelsea Hospital, London); Infection and poor outcome of pregnancy-Mr R. Lamont (Northwick Park Hospital, Harrow); Microbial aspects of pregnancy wastage-Professor D. Taylor-Robinson (St Mary's Hospital, London); Transmission of HIV from mother to baby-Dr J. Peutherer (Edinburgh University Medical School); The TORCH light flickers - diagnosis of congenital infections-Dr Diana Westmoreland (University Hospital of Wales).

12.50 LUNCH (Refreshments provided).

13.50 Bacterial infections on special care baby unit-Dr Gabriella Phillips (Ninewells Hospital, Dundee); Antibiotic policies for the neonatal unit-Dr R. Masterton (Western General Hospital, Edinburgh).

15.00 FOUNDATION LECTURE - to be given by Professor Robin Weiss entitled 'Retroviruses for good and ill'.

The symposium is open to members of the College, to trainee pathologists and to workers in other disciplines with an interest in the subject. The programme is approved by the Thames Postgraduate Deans and hospital doctors may apply to their employing authority for Study Leave under $\operatorname{HM}(67) 27$.

The registration fee is $£ 45$ and includes coffee, lunch and tea.

Details and application forms may be obtained from:

Maureen Russell

Royal College of Pathologists

2 Carlton House Terrace

LONDON SW1Y 5AF

Tel: 01719305862 (Ext: 25/25) 


\section{Options for the Control of Influenza III}

4-9 May, 1996

Cairns, North Queensland, Australia

The Third International Conference in the series 'Options for the Control of Influenza' will be held in Cairns in May 1996.

The conference will build on the highly successful multidisciplinary format established at the meetings conducted in 1985 and 1992 at Keystone, USA, and Courchevel, France, and will bring together workers involved in all aspects of influenza from basic research through development and licensing of new vaccines and therapeutics, to epidemiology and control programs.

The Chairman of the Local Organising Committee and Congress Secretary is: Alan W. Hampson (WHO Collaborating Centre for Influenza)

Tel: 61338913450 Fax: 6133882063

Further information can be obtained from:

Influenza '96 Conference Secretariat,

GPO Box 128, Sydney, NSW, 2001, Australia.

Tel: 6122622277 Fax: 6122622323

Email: TourHosts@TourHosts.COM.AU 